\title{
An Integrated Approach of the Potential Underlying Molecular Mechanistic Paradigms of SARS-CoV-2-Mediated Coagulopathy
}

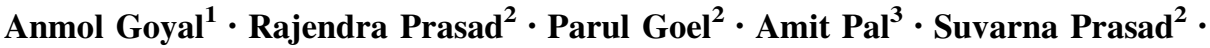 \\ Isha Rani ${ }^{2}$
}

Received: 13 December 2020/Accepted: 3 April 2021/Published online: 15 April 2021

(C) Association of Clinical Biochemists of India 2021

\begin{abstract}
Coronavirus disease 2019 (Covid-19) caused by severe acute respiratory syndrome coronavirus 2 (SARSCoV-2) is a pandemic disease which has affected more than 6.2 million people globally, with numbers mounting considerably daily. However, till date, no specific treatment modalities are available for Covid-19 and also not much information is known about this disease. Recent studies have revealed that SARS-CoV-2 infection is associated with the generation of thrombosis and coagulopathy. Fundamentally, it has been believed that a diverse array of signalling pathways might be responsible for the activation of coagulation cascade during SARS-CoV-2 infection. Henceforth, a detailed understanding of these probable
\end{abstract}

Isha Rani

singlaisha8@gmail.com

Anmol Goyal

anmolgoyal01.ag@gmail.com

Rajendra Prasad

fateh1977@yahoo.com

Parul Goel

paru1006@gmail.com

Amit Pal

maximus1134@gmail.com

Suvarna Prasad

suvarnaprasad999@gmail.com

1 Department of Community Medicine, Gian Sagar Medical College and Hospital, Ram Nagar, Rajpura, Patiala, Punjab, India

2 Department of Biochemistry, Maharishi Markandeshwar Institute of Medical Sciences and Research (MMIMSR), Maharishi Markandeshwar University (MMU), Mullana, Ambala, Haryana, India

3 Department of Biochemistry, AIIMS, Kalyani, West Bengal 741235, India underlying molecular mechanistic pathways causing thrombosis in Covid-19 disease deserves an urgent exploration. Therefore, in this review, the hypothetical crosstalk between distinct signalling pathways including apoptosis, inflammation, hypoxia and angiogenesis attributable for the commencement of thrombotic events during SARS-CoV-2 infection has been addressed which might further unravel promising therapeutic targets in Covid-19 disease.

Keywords SARS-CoV-2 · Covid-19 • Coagulopathy · Hypoxia $\cdot$ Apoptosis $\cdot$ Inflammation $\cdot$ Angiogenesis

$\begin{array}{ll}\begin{array}{l}\text { Abbreviations } \\ \text { SARS-CoV-2 }\end{array} & \begin{array}{l}\text { Severe acute respiratory syndrome } \\ \text { coronavirus } 2\end{array} \\ \text { ACE-2 } & \begin{array}{l}\text { Angiotensin-converting enzyme 2 } \\ \text { Tissue factor }\end{array} \\ \text { TF } & \text { Plasminogen activator inhibitor-1 } \\ \text { PAI-1 } & \text { Urokinase } \\ \text { uPA } & \text { Tissue plasminogen activator } \\ \text { tPA } & \text { Antithrombin } \\ \text { AT } & \text { Activated protein C } \\ \text { APC } & \text { Phosphatidylserine } \\ \text { PS } & \text { Nuclear factor-kappa B } \\ \text { NF- } \kappa \text { B } & \text { Hypoxia inducible factors } \\ \text { HIFs } & \text { Vascular endothelial growth factor } \\ \text { VEGF } & \text { Phosphoinositide-3-kinase } \\ \text { PI3K } & \text { Protein kinase B } \\ \text { AKT } & \end{array}$




\section{Introduction}

Coronavirus disease 2019 (Covid-19), a respiratory illness caused by severe acute respiratory syndrome coronavirus-2 (SARS-CoV-2) was firstly emerged in Wuhan city, China and subsequently resulted in an ongoing pandemic. According to WHO Covid-19 dashboard, approximately 64,603,428 confirmed cases and 1,500,614 deaths cases were reported globally up to 4th December, 2020 (available at https://covid19.who.int). The range of Covid-19 infection is extensive with regularly encountered complications including pneumonia, sepsis and acute respiratory distress syndrome (ARDS) (available at https://www.cdc.gov). The major burden is constantly escalating the rate of mortality owing to Covid-19 infection. Till date, there are no potential therapeutic modalities or vaccines available to deal with Covid-19 pandemic. Therefore, it is urgently required to explore additional biotherapies which may primarily target SARS-COV-2 virus and eventually impact morbidity and mortality burden. It is assumed that the development of novel treatment strategies could be only possible after detailed understanding of pathophysiology of SARS-CoV-2 in the human system. In the recent scenario, thrombotic complications appear to arise as a major concern in Covid-19 subjects and are increasingly gaining attention. Interestingly, the severity of Covid-19 infection has been interconnected with the severity of coagulopathy with high rates of venous and arterial thrombosis, progression to critical illness and mortality [1,2]. Additionally, the pathophysiological course of events related to microvascular thrombosis in Covid-19 patients provides an elucidation of life threatening complications related to cerebrovascular, myocardial ischemia, microcirculatory and macrocirculatory thromboembolic [3]. Strikingly, the better understanding about detailed description of the potential triggers responsible for Covid-19-associated coagulopathy is underlined. With this background, the present review article will focus on possible underlying molecular mechanisms of coagulopathy caused by SARSCoV-2. It is believed that comprehensive understanding of distinct downstream mechanistic pathway involving apoptosis, inflammation, hypoxia and angiogenesis accountable for coagulopathy involving thrombotic manifestations may provide novel therapeutic strategies to combat Covid19 infection.

\section{Overview of Coagulation Process}

Endothelial cells play a prominent role in maintaining the homeostasis, keep blood in a fluid state and also act in response to coagulation during injury in order to prevent exsanguination [4]. Therefore, it is mandatory to maintain a perfect balance between pro- and anti-coagulant factors to carry out proper functioning of the physiological system. The process of formation of blood clot is highly ordered and it involves three important components i.e. endothelial cells, platelets and coagulation factors. It occurs in sequential manner through primary homeostasis, secondary homeostasis/coagulation and fibrinolysis. Generally, initiation of clotting process arises in response to any damage to the vasculature and in turn, stimulates platelet activating- and pro-coagulant factors. Primary homeostasis is based on the formation of homeostatic platelet plug due to von willebrand factor (VWF), as a sensitive marker for the activation of endothelial cells whereas during injury, activated platelets further foster secondary homeostasis by offering cell-surface phospholipids. Secondary homeostasis essentially serves to activate the coagulation system leading to formation of covalently cross-linked fibrin which eventually strengthen platelet plug and lead to a stable platelet-fibrin clot. It is regulated through two different initial pathways such as contact activation (intrinsic) pathway and tissue factor (TF) dependent (extrinsic) pathway which converge at factor $\mathrm{X}$ to induce thrombus formation by conversion of fibrinogen to fibrin (Fig. 1i). The coagulation cascade is regulated by numerous protein factors present in an inactive state. The intrinsic coagulation pathway is usually triggered by factors completely restricted within the vasculature which results in the contact induction of factor XII (FXII) followed by the subsequent activation of various downstream protein reactions responsible for formation of prothrombin to thrombin and eventually, fibrin network. Conversely, the extrinsic system or TF dependent pathway is considered as the principal in vivo blood coagulation pathway which involves the role of both blood and vascular elements. Tissue factor (sometimes also refer as thromboplastin), a transmembrane glycoprotein complex in response to vascular endothelial cell damage activates factor FVII (FVIIa; proconvertin) which causes proteolytically induction of diverse inactive factors such as FIX to IXa and FX to Xa and ultimately, participates in the conversion of fibrinogen to fibrin. Interestingly, coagulation cascade is controlled by varied inhibitory pathways. The first mechanism comprises of circulating pro-coagulant inhibitors including inhibitors of thrombin such as anti-thrombin and heparin cofactor II as well as inhibitor of tissue factor (TFI) pathway. There are other two circulating coagulation inhibitors such as protein $\mathrm{C}$ and protein $\mathrm{S}$, a cofactor of activated protein C (APC). On the other hand, second inhibitory mechanism proceeds through endothelium bound modulators such as heparin sulphate and thrombomodulin which further augment the inhibitory activity of antithrombin and protein $\mathrm{C}$ respectively. The third inhibitory pathway, typically known as 
fibrinolytic system is profoundly involved in the degradation of the fibrin strands. This system is initiated by tissue plasminogen activators (tPA) and urokinase (uPA) which converts plasminogen to plasmin, and hydrolyses polymerised fibrin strands into soluble fibrin degradation products, thus degrading the fibrin clot. It is not surprising that any massive activation of the coagulation system results in a subsequent increase in the blood clotting and eventually consumptive coagulopathy or even disseminated intravascular coagulation (DIC). Most importantly, DIC, characterized by activation of the coagulation system is accompanied by inhibition of anticoagulant mechanisms, constituting the accessibility of antithrombin, decreased activity of protein C-protein S-thrombomodulin system and impairment in the fibrinolytic response which slows down the coagulation mechanism $[5,6]$.

Furthermore, various clinical and molecular studies have postulated the linkage of viral infection and thrombotic risk. The endothelial injury is a paramount characteristic of viral infection and this alters homeostasis directly or indirectly [7]. Consistent with this notion, impairment in coagulation and fibrinolysis mechanisms has been observed in a number of viral infections such as ebola virus [8] and dengue virus [9], herpes simplex, adenovirus, parainfluenza virus, echovirus, poliovirus, measles, human immunodeficiency virus(HIV), mumps, cytomegalovirus(CMV), and human T-cell leukemia virus which may impair coagulation by directly infecting the endothelial cells [8, 10-14].

\section{Implication of SARS-CoV-2 in Coagulation Process}

It is well established that respiratory tract exposure is the major route of SARS-CoV-2 transmission. Generally, SARS-CoV-2 enters host cells via the binding of viral spike (S) proteins to angiotensin-converting enzyme 2 (ACE2) receptors, a metallopeptidase and $\mathrm{S}$ protein priming for the serine protease, Transmembrane protease, serine 2 (TMPRSS2) $[15,16]$. ACE2 is a homolog of ACE which converts angiotensin II to angiotensin 1-7, responsible for mitigating renin-angiotensin system-related vasoconstriction. Notably, ACE2 is broadly expressed in variety of human organs including nasopharynx, oropharynx, lungs, stomach, small intestine, spleen, liver, kidney and brain. However, ACE2 receptors are densely present in the lungs, heart, veins and arteries [17].

During direct damage of endothelial cells, SARS-CoV-2 also supposed to enter the lungs via the endothelial cells. SARS-CoV-2 exploits ACE2 receptors for their direct entry into endothelial cells and thereby leads to direct injury of endothelial cells. The expression of ACE2 receptors for SARS-CoV-2 has been observed in arterial and venous endothelial cells in various human tissues [16, 17]. Likewise, the expression of TMPRSS-2 has been also previously reported in human endothelial cells which may alter among microvascular and macrovascular beds as well as across organs [18]. Researchers have visualized viral inclusion structures in endothelial cells using electron microscopy. In spite of ACE2, other receptors such as CD209L and vimentin which have been suggested to act as recognized receptors of SARS viruses are expressed in endothelial cells [19, 20]. Notably, it has also been proposed that SARS-CoV-2 may also be transported via airborne particulate matter (diameter $\leq 2.5 \mu \mathrm{m}$ ) to endothelial cells which traverse the alveolar-capillary barrier followed by deposition on the vascular endothelium via specific receptors [21, 22].

Consequently, endothelial damage during SARS-CoV-2 entry leads to shift in the balance of the vasculature towards vasoconstriction and thereby, causing organ ischaemia, tissue oedema, accountable for inflammation and a procoagulant state. This statement is also further corroborated by numerous other clinical studies reporting prevalence of thromboembolic anomalies as well as coagulopathy including venous thromboembolism, pulmonary embolism and disseminated intravascular coagulation (DIC) in Covid-19 patients [23]. Likewise, the prevalence of these coagulation abnormalities or formation of intraalveolar or systemic fibrin clots in SARS-CoV-2 infected patients with severe respiratory disease has been attributable to vascular inflammation and endothelial defect which finally contribute to the onset and development of endothelial dysfunction as well as defective coagulation. Basically, the participation of dysfunctional endothelial cells in above mentioned thrombo-inflammatory processes may predispose the consequences of Covid-19 induced vasculopathy as well as clinical phenotype of ARDS.

Recent autopsy studies of Covid-19 patients have observed fibrin thrombi within distended small vessels as well as capillaries and widespread extracellular fibrin deposition. Recent study has confirmed that venous thromboembolism (VTE) rate is $4.8 \%$ and the overall thrombotic complication rate is $9.5 \%$ in Covid-19 patients [24]. However, other study has observed $31 \%$ prevalence of thrombotic events in 184 severe cases of Covid-19 disease [25]. Preliminary clinical studies have reported that patients infected with Covid-19 usually onset thrombocytopenia and also display raised D-dimer ( $>1000 \mathrm{ng} / \mathrm{mL}$ ), fibrin degradation products or fibrinogen factor VIII, or von willebrand factor $(>150 \mathrm{U} / \mathrm{mL})$, prolonged prothrombin time $(>16 \mathrm{~s})$, disseminated intravascular coagulopathy (DIC) which become even higher with escalating severity of Covid-19 illness [24]. Most notably, elevated levels of D-dimer and fibrin degradation products are considered as 
reliable predictive marker for the risk of a thrombotic event and mortality rate in Covid-19 patients [25]. Moreover, in combination, platelet count $(>450 \times 109 / \mathrm{L})$, C-reactive protein $(\mathrm{CRP} ;>100 \mathrm{mg} / \mathrm{L})$ and erythrocyte sedimentation rate $(\mathrm{ESR} ;>40 \mathrm{~mm} / \mathrm{h})$, fibrinogen $(>400 \mathrm{mg} / \mathrm{dl})$, ferritin $(>500 \mu \mathrm{g} / \mathrm{L})$ and procalcitonin $(>0.5 \mu \mathrm{g} / \mathrm{L})$ are also mentioned as additional markers for the prediction of thrombosis in hospitalized Covid-19 patients [24].

\section{Possible Involvement of Several Molecular Mechanistic Strategies during SARS-CoV-2- Mediated Coagulation}

\begin{abstract}
Although the relationship between SARS-CoV-2 and coagulation has been addressed but the molecular mechanisms attributable for the coagulation related complications during SARS-CoV-2 infection has not been investigated. But it seems to be regulated by several pathways related to apoptosis, inflammation, hypoxia and angiogenesis. Henceforth, in the following section of this review article, the detailed potential role of myriad molecular signalling pathways related to aforementioned parameters has been elucidated which might assist to perceive therapeutic targets for evading Covid-19 infection.
\end{abstract}

\section{Role of Apoptosis in SARS-CoV-2-Mediated Coagulation}

In vitro human and animal studies have demonstrated that diverse stimuli including viral provoked programmed cell death of endothelial cells of the vasculature is suggestive of apoptosis as one of important mechanisms triggering vascular injury, vascular leak, inflammation and coagulation. In vitro studies revealed that adherens junction proteins are degraded followed by disruption in barrier function during endothelial cell apoptosis [27]. Subsequently, in vivo it can result in vascular leak and stimulate inflammation in the neighbouring tissues by plasma components including complement and coagulation constituents. Moreover, apoptotic endothelial cells can also become pro-adhesive for platelets and leukocytes [28, 29] as well as pro-coagulant [30] which further facilitatecoagulation. Importantly, if apoptotic cells are cleared efficiently, they become procoagulant and lead to thrombotic disorders [30, 31].

SARS-CoV-2 may infect endothelial cells expressing receptor ACE2 molecule for viral adhesion. In addition to affecting immune and inflammatory status, it also results in induction of endothelial apoptosis. SARS-CoV-2 ORF3aSARS-CoV-encoded accessory protein ORF3a showed weaker pro-apoptotic activity in cells [32]. The apoptosis of endothelial cells can perturb crucial cellular mechanisms
4 Fig. 1 i. A detailed overview of tissue factor (TF) dependent (extrinsic) and contact activation (intrinsic) coagulation pathway- The coagulation process is an intricate process regulated through a series of clotting factors. In TF dependent (extrinsic) cascade, the endothelial cells release TF which convert factor VII to factor VIIa and subsequently factor VIIa convert factor X into active form of factor $\mathrm{Xa}$. On the other hand, the contact activation (intrinsic) coagulation pathway initiates with the activation of a zymogen factor XII-XIIa via the participation of kinin-kallikrein system in response to endothelial damage. The factor XIIa acts as a catalyst to convert factor XI to factor XIa. Further, factor XIa then goes on to convert factor IX to factor IXa. Finally, factor IXa turns inactive factor X into active factor Xa. Both intrinsic and extrinsic pathway converges at one point which is factor Xa and so known as common pathway. The activated factor $\mathrm{Xa}$ cleaves prothrombin into thrombin by the involvement of factor V. Further, thrombin transforms fibrinogen into fibrin by factor XIIIa which in turn form fibrin mesh to stabilize the platelet plug. *Antithrombin (AT) prevents coagulation by inhibiting thrombin and factor XIIIa. *Plasmin also hinders the formation of stabilized fibrin clot by activating the process of fibrinolysis. *The activated protein C (APC) and activated protein S (APS) anticoagulant system also act to prevent coagulation, especially by inactivating factors V and VIII. ii. Proposed schematic diagram showing underlying mechanism of SARS-CoV-2 mediated apoptosis which can modulate coagulation cascade- a SARS-CoV-2 enters via ACE-2 receptor of endothelial cells and might induce apoptotic stimuli by ORF3a SARS-CoV-encoded accessory protein ORF3a. b In endothelial cells, anionic phosphatidylserine (PS) is generally sequestered in the cytoplasmic inner leaflet of the plasma membrane by 'flippase' while external apoptotic response stimulates the translocation/exposure of PS from inner to the outer leaflet through lipid transporter via 'scramblase'. c and d Interestingly, translocation of PS to the outer leaflet will activate TF (extrinsic) dependent coagulation pathway through conversion of inactive factor (FVII) to active form (VIIa) as well as also promote contact activation (intrinsic) coagulation pathway via the activation of various zymogen factors (FXII, FXI, FIX) to its active forms (XIIa, XIa, IXa) which finally converge at common pathway via activation of $\mathrm{FX}$ to $\mathrm{Xa}$, prothrombin to thrombin, fibrinogen to fibrin and eventually stabilized fibrin clots and thrombus. The dashed arrow $(---\rightarrow)$ designates mechanistic pathway undergo through numerous steps and soild arrow (-) shows common transformations from one active factor to another factor. Green arrow ( $\longrightarrow$ ) describes activation whereas red blunt arrow (_ $)$ indicates inhibition. Abbreviations-TF: tissue factor, PAI-1: plasminogen activator inhibitor-1, Upa: urokinase, tPA: tissue plasminogen activator, AT: antithrombin, APC: activated protein C, APS: activated protein S, SARS-CoV-2: severe acute respiratory syndrome coronavirus 2, ACE-2: angiotensin-converting enzyme 2, PS: phosphatidylserine, ORF3a: SARS-CoV-encoded accessory protein ORF3a

maintaining the biocompatibility shield between the circulating blood flow and tissues. As already discussed in detail, apoptosis of endothelial cells can trigger complications of coagulation as well as development of prothrombotic state including local and disseminated thrombus formation [33]. It was evidenced with endothelial cell 


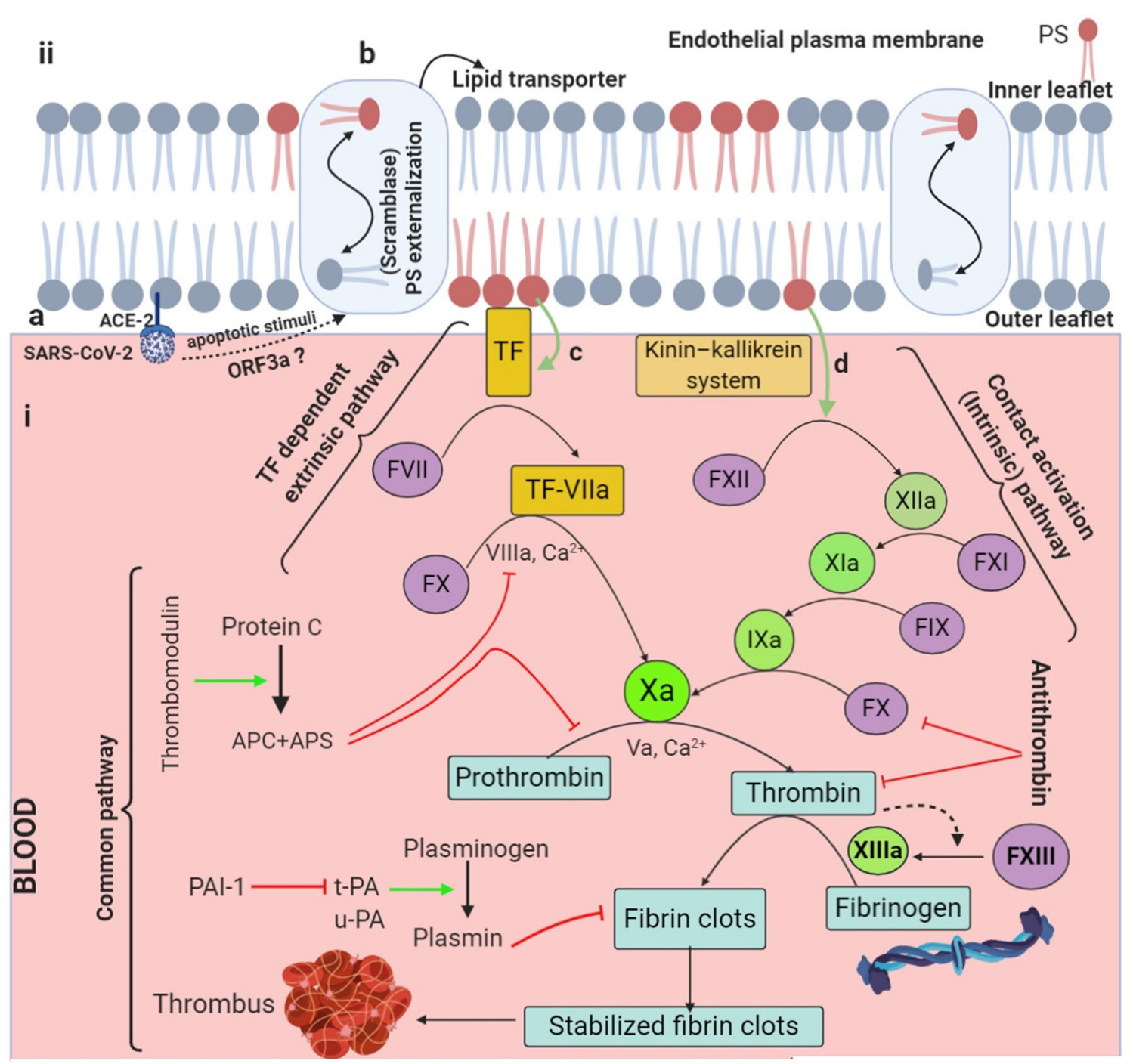

death after SARS-CoV-2 infection directly or immune mediated through histopathological analysis [34]. Colmenero et al. has also proposed that endothelial cell damage and endotheliitis induced by SARS-CoV-2 could be a key mechanism for vascular damage during pathogenesis of COVID-19 chilblains [35]. An early onset of rapid viral replication has been linked with massive endothelial cell apoptosis and vascular leakage [36]. Recent studies have demonstrated that SARS-CoV-2 induces endothelial cell death which further augments the process of thrombosis and simultaneously, leads to ARDS and multiorgan failure [37, 38].

Several apoptotic endothelial cell-mediated mechanisms have been suggested to be responsible for predisposition of prothrombotic state. One of the important mechanisms is related to alterations in asymmetry of phospholipid bilayer including outer exposure of anionic phospholipid phosphatidylserine (PS) which is a fundamental feature of apoptosis. PS externalization occurs through caspase mediated cleavage and inactivation of the 'flippase' and activation of 'scramblase', another lipid transporter protein which is induced by activated caspases [39]. Concomitantly, PS exposure to the outer leaflet in apoptotic cells stimulate the coagulation pathway which have been widely observed in number of apoptotic cells including endothelial cells and many other cells [40] (Fig. 1ii).

The exposed PS exhibits a shorter coagulation time as well as an increased FXa, thrombin and fibrin formation. Experimental evidence has showed that translocated PS on uremic endothelial cell outer surface offered membranebinding sites for $\mathrm{FVa} / \mathrm{FXa}$ and also favours the assembly of prothrombinase complex, thrombin generation and fibrin deposition [41]. The exposed PS provides the pro-coagulant surface as a docking site for the generation of various active enzyme-substrate complexes of the coagulation cascade, particularly tenase [active factor IX (IXa), its 
cofactor factor VIII (VIIIa), the substrate (factor X) and calcium ions] and prothrombinase complexes [active factor $(\mathrm{Xa})$, its cofactor factor $(\mathrm{Va})$, prothrombin, calcium ions and platelet phospholipids] .

The presence of PS on outer leaflet of plasma membrane of apoptotic cells provides a catalytic site for the activator of the contact activation (intrinsic) system, FXII which may undergo auto-activation and contribute to apoptosis related procoagulant activity. Indeed, it is also believed that PS may also recruit two other components of contact activation system such as prekallikrein and kininogen which further increase the activation of FXII [42]. The activated FXII further leads to the formation of intrinsic tenase complex and eventually, promotes blood clotting. Therefore, it can be inferred that apoptotic cell membrane may serve as a catalytic surface for assembly and activation of the contact activation system .

Additionally, apoptotic cells have been also reported to stimulate the coagulation system by upregulating the surface expression of tissue factor (TF), an initiator for the extrinsic coagulation cascade [43]. It has been postulated that apoptosis associated with cell membrane alterations would result in an enhanced procoagulant activity of TF [44]. In consistent with this fact, PS in the outer leaflet of the apoptotic cell has been reported to maintain the activity of $\mathrm{TF}$ at the cellular surface [45]. Although it is well documented that PS remarkably augments the enzymatic activity of TF-FVIIa towards its substrates such as factors IX and X [46], but the molecular mechanisms of this phenomenon is still not known. Upon injury to endothelial cells, TF, a membrane bound cofactor comes in contact with circulating blood followed by interaction with FVII which causes further subsequent activation of the coagulation pathway. Simultaneously, apoptotic cell death also lead to the release of microparticles, spherical structures of size between 100 and $1000 \mathrm{~nm}$ made up of outer cell membrane. These microparticles can externalize PS and express membrane antigens on their surfaces [47]. The exposure of PS on cells and MPs provides binding sites for factor FXa and prothrombinase complex and thereby initiates coagulation cascade. Moreover, TF-bearing microparticles also display profound characteristics of procoagulant state by engaging PS [48].

However, viable comprehensive mechanistic approach of apoptosis in inducing coagulation during SARS-CoV-2 infection is still need to be investigated. It has been hypothesized that the detailed mechanism may be followed by SARS-CoV-2 to initiate apoptosis mediated coagulation and indeed, might prove beneficial to identify therapeutic targets against SARS-CoV-2 related coagulopathy .

\section{Effect of Inflammatory Response on SARS-CoV-2- Mediated Coagulation}

Remarkably, viral infections elicit systemic inflammatory as well as endothelial dysfunction response which results in imbalance between procoagulant and anticoagulant homeostatic pathways. It is noteworthy that persistent inflammatory status in severe cases of SARS-CoV-2 infection may act as one of the most imperative activator for the coagulation cascade. Thus, it has been speculated that SARS-CoV-2 virus might exploit inflammatory mechanistic approach in order to mediate thrombotic events (Fig. 2). SARS-CoV-2 infection influence extensively both innate and adaptive immune defense system [49]. Indeed, an innate immune response protects host cells from initial infection and takes place well before the onset of adaptive response. The innate defense system comprises of specialized proteins and various cellular components such as dendritic cells (DCs), macrophages, and natural killer (NK) cells. During viral infection, these activated innate cells typically recognize an extensive array of viral products using pattern-recognition receptors (PRRs) and induce transcription factors including activator protein 1 (AP 1), nuclear factor kappa-light-chain-enhancer of activated $\mathrm{B}$ cells $(\mathrm{NF}-\mathrm{\kappa B})$ and interferon regulator factors (IRF3 and IRF7) which are accountable for production of interferons (IFNs), pro-inflammatory cytokines and chemokines. The recruitment of receptor-interacting protein 1 (RIP1) and TNF receptor-associated factors 2 and 6 (TRAF2/6) may activate transcription factors such as NF- $\kappa \mathrm{B}$ and AP1. This pathway finally degrades inhibitor of $\kappa B$ (I $\mathrm{KB}$ ) which thereby, releases NF- $\kappa B$ which is attributable for overproduction of pro-inflammatory cytokines [interleukin (IL)-6, IL-1 $\beta$, IL-8 and tumour necrosis factor alpha (TNF$\alpha)$ ], also known as 'cytokine storm' and chemokines [50]. On the basis of previous literature, NF- $\mathrm{KB}$, is the main gauge of cytokine storm during inflammatory conditions [50, 51]. It is believed that the onset of inflammatory storm further may lead to endothelial dysfunction, inflammation and disseminated intravascular coagulation (DIC), responsible for alveolar dysfunction, ARDS and ultimately multi-organ failure and death. These consequences are corroborated by evidences showing DIC in the severe cases of Covid-19 infection [28, 52].

A number of mechanistic pathways have been proposed regarding the close association of pro-inflammatory response including immune components in the coagulation processes (Fig. 2). Importantly, systemic inflammation can stimulate coagulation cascade by activating thrombin generation, down-regulating anticoagulant mechanisms, as well as inhibiting fibrinolysis in a positive feedback loop manner. During inflammatory response, innate immune 


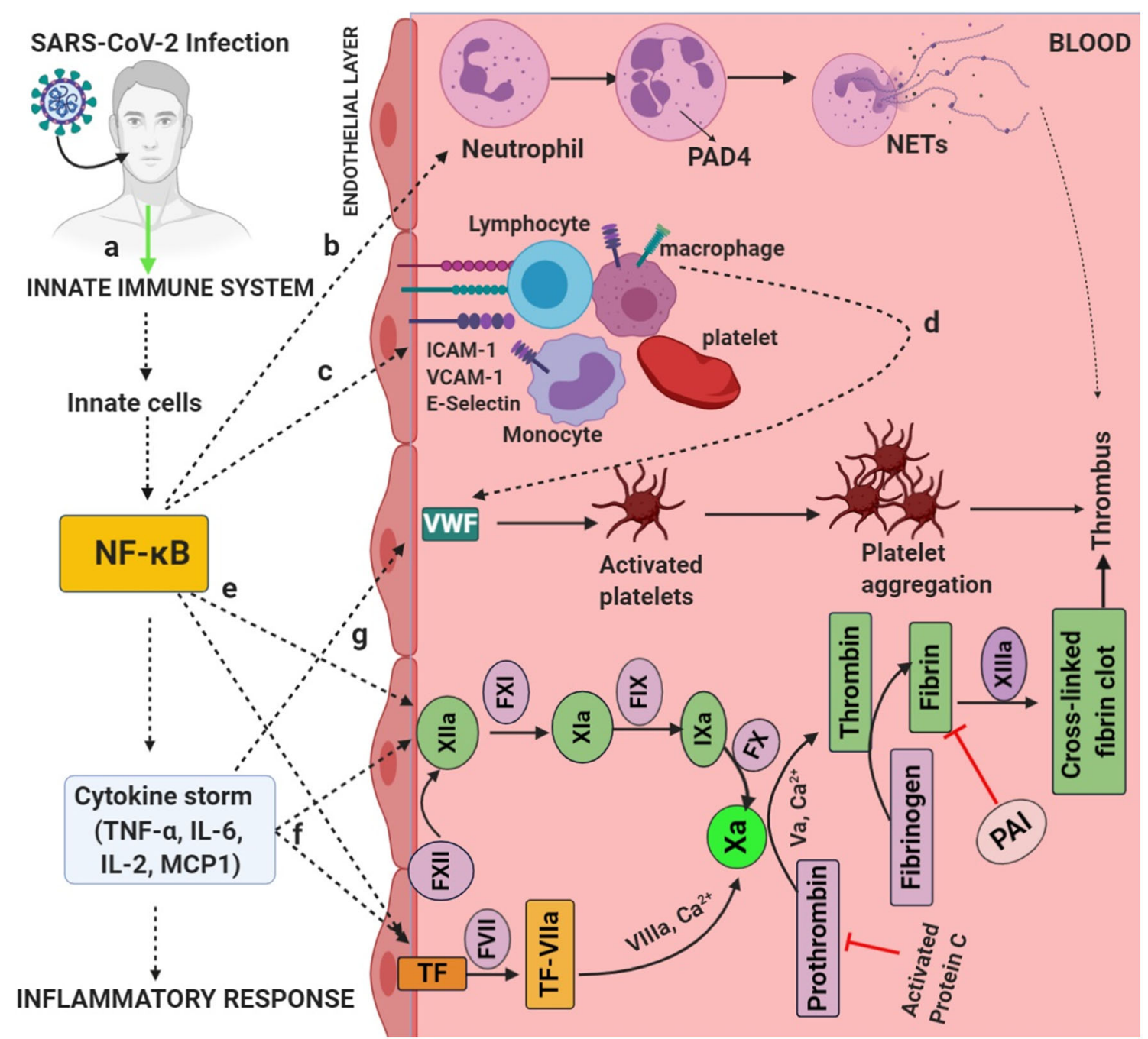

Fig. 2 . Probable diagrammatic description of the basic mechanism of SARS-CoV-2 infection induced inflammation mediating coagulation pathway- a SARS-CoV-2 infection has been reported to be associated with an increased activation of innate immune system which are known to activate NF- $\kappa B$, a key transcription factor that activates numerous genes involved in the cellular immune response responsible for 'cytokine storm' (TNF- $\alpha$, IL- 6 , IL-2 and MCP1) and inflammation. NF- $\kappa B$ signalling cascade in endothelial cells is capable of regulating both pro-inflammatory and coagulatory responses. b NF- $\kappa B$ triggers neutrophils which upon full activation expel their DNA in conjunction with histones and other associated proteins and lead to the formation of NETs via PAD4-mediated histone citrullination responsible for inducing a strong coagulatory response. $\mathbf{c}$ the target genes of NF- $\kappa \mathrm{B}$ are cell adhesion molecules (CAMs) such as ICAM-1, VCAM-1 and E-selectin which are expressed on the surface of endothelial cells and intervene the adherence as well as transmigration of leukocytes including monocytes, neutrophils, lymphocytes, macrophages and platelets to the vascular wall and this further triggers increasing their thrombogenic potential. d The infiltration of inflammatory cells and leukocyte-platelet conjugates to the endothelium activates VWF, an another important

cells including monocytes and neutrophils may mediate $\mathrm{TF}$ expression, causing the subsequent activation of coagulation process $[53,54]$. The inflammatory activation of prothrombotic factor on the endothelium which allows the aggregation of platelets leading to the thrombus formation, $\mathbf{e ~ N F - \kappa B}$ is known to activate the transcription of various targeting genes significant to thrombosis including TF and FXII which ultimately converge at common pathway of the thrombus synthesis. $\mathbf{f}$ cytokine storm induced by NF- $\kappa \mathrm{B}$ is also known to modulate both TF dependent and contact activation pathway. $\mathbf{g}$ cytokine storm also activates VWF, a prothrombotic factor for platelets aggregation responsible for the thrombus formation. The dashed arrow $(----\rightarrow)$ entitles respective pathway comprises of multiple steps and soild arrow $(\longrightarrow$ ) shows general alterations in respective pathway. Green arrow $(\longrightarrow$ ) shows activation whereas red blunt arrow ( $\longrightarrow$ ) denotes inhibition Abbreviations-SARS-CoV-2: severe acute respiratory syndrome coronavirus $2, \mathrm{NF}-\kappa \mathrm{B}$ : nuclear factor- kappa $\mathrm{B}$, TNF- $\alpha$ : tumor necrosis factor- $\alpha$, IL-6: interleukin-6, IL-2: interleukin-2, MCP1: monocyte chemoattractant protein-1, NETs: neutrophil extracellular traps, PAD4: peptidylarginine deiminase 4, CAMs: cell adhesion molecules, ICAM-1: intercellular adhesion molecule-1, VCAM-1: vascular cell adhesion molecule-1, VWF: von willebrand factor

neutrophils triggers the contact pathway of coagulation via FXI and FXII which form neutrophil extracellular traps (NETs) with the clusters of DNA, histones and other 
associated proteins [55]. Furthermore, NETs have been observed in vessels in the autopsy specimens of Covid-19 patients [56]. On the other hand, NF- $\kappa B$ signalling cascade is capable of regulating pro-adhesive and pro-coagulant phenotypes owing to its involvement in endothelial cells in response to stress conditions. In vitro studies have revealed that important proinflammatory cytokines [including TNF$\alpha$, IL-1 $\beta$, Interferon gamma (IFN)- $\gamma]$ and thrombin are the strong activator of NF- $\kappa \mathrm{B}$ in endothelial cells [57]. In endothelial cells, NF- $\mathrm{KB}$ drives full expression of adhesion molecules such as intercellular adhesion molecule 1 (ICAM-1), vascular cell adhesion molecule 1 (VCAM-1) and endothelial-leukocyte adhesion molecule-1 (E-selectin) which facilitate adherence of inflammatory cells including monocytes, neutrophils, lymphocytes, and macrophages to the vascular wall [58-60]. Additionally, NF$\kappa \mathrm{B}$ also mediates the expression of coagulation factors such as factor VIII and TF in combination with a concomitant decrease in anticoagulatory factors including TF pathway inhibitor (TFI), antithrombin or thrombomodulin [61]. It results in the activation of both the extrinsic and intrinsic coagulation cascade, leading to the thrombin generation and finally coagulation. Interestingly, thrombin induces NF- $\mathrm{KB}$-dependent genes which forms a positive feedback loop and further intensify coagulation [62]. Moreover, at the same time, NF- $\kappa \mathrm{B}$ impairs fibrinolysis by mediating type 1 plasminogen-activator inhibitor (PAI-1) expression which is indicative of an activated coagulation process. Thus, induction of NF- $\kappa B$ may display clinical manifestations of sepsis, DIC and multiple organ dysfunction [63].

Since NF- $\mathrm{BB}$ triggers the release and/or the generation of myriad pro-inflammatory cytokines in a positive feedback loops which further results in so-called 'cytokinestorm' [64]. These pro-inflammatory cytokines exert a pivotal role in the coagulation, anticoagulant and fibrinolysis mechanisms at multiple levels during DIC and sepsis. In vitro studies have observed that a number of cytokines such as TNF- $\alpha$, IL- $1 \alpha$, IL-1 $\beta$, IL-6, IL-8, leukemia inhibitory factor, IFN- $\gamma$ and monocyte chemoattractant protein 1 (MCP-1) stimulate TF formation and von willebrand factor (VWF) from endothelial cells and monocytes, activators of coagulation cascade [65]. During viral infection, cytokines also exert direct chemotactic effects on the infiltration of NK cells which increases their binding to vascular endothelial cells. Numerous experimental results and observational studies have supported a link between IL-6 and increased risk of vascular thrombosis and thromboembolism [66]. During an early phase of inflammatory response, IL-6 induces the release of pro-inflammatory cytokine/chemokines (IL-6, IL-8, MCP-1) by endothelial cells [67] and hence, causing endothelial dysfunction, accountable for capillary leakage, hypotension, and coagulopathy [66]. Moreover, cytokines can also influence the protein C-protein S-thrombomodulin system which overall impairs the anticoagulant function. Endothelial cell culture and animal studies have indicated that TNF- $\alpha$ and IL-1 enhance the pro-coagulant response by down regulating expression of thrombomodulin and protein $\mathrm{C}$ synthesis $[68,69]$. In vitro reports have shown that both TNF- $\alpha$ and IL-1 act as anti-fibrinolytic components by inducing PAI-1 production in the vascular endothelium which is indicative of the rapid inactivation of fibrinolysis [70]. In context to these results, cytokines such as IL-1 $\beta$, IL- 6 and IL-2 has been reported to cause hypercoagulation and activation of coagulation cascade in Covid-19 patients with severe symptoms [71, 72]. The role of IL-2 in the pathophysiology of Covid-19 has been supposed to be implicated owing to its direct action on the endothelium. Moreover, elevation in TNF- $\alpha$ levels has also been correlated with coagulation dysregulation in patients infected with SARS-CoV-2 virus [73].

With this background, it has been supposed that SARS$\mathrm{CoV}-2$ can exploit NF- $\kappa \mathrm{B}$-mediated signalling mechanism to promote thrombotic events and hence, NF- $\kappa \mathrm{B}$ or its

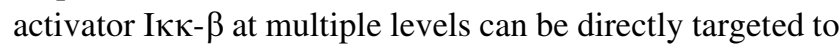
deal with SARS-CoV-2 -mediated coagulation. Henceforth, it is mandatory to carry out extensive research to evaluate the possible role of inflammatory signalling axis on thrombotic mechanism in Covid-19 disease which might direct future therapeutic strategies to deal with SARS-CoV-2-associated coagulation.

\section{Role of Hypoxia Mediated Coagulation during SARS-CoV-2 Infection}

Hypoxic conditions generally establish during trauma related to respiratory diseases including chronic obstructive pulmonary disease (COPD), emphysema, bronchitis, pneumonia, and pulmonary edema. Interestingly, Covid-19 disease, a respiratory illness also displays the characteristics of hypoxia and dyspnea conditions [74]. Clinical and laboratory studies have revealed that Covid-19 induced hypoxia can facilitate overt clot formation which affect the survival and mortality rate in patients [75]. A contemporary study has also postulated that extracellular RNA (eRNA) of SARS-CoV-2 could activate hypercoagulation via Toll-like receptors 3 (TLR3) mediated signalling under hypoxic conditions [76]. Earlier studies have revealed a number of ways are responsible for induction of hypoxia mediated coagulation. Therefore, it is thought that SARSCoV-2 may utilize these multiple pathways, attributable for SARS-CoV-2-mediated coagulation under hypoxic conditions (Fig. 3). 
During viral infection, hypoxia triggers hypoxia-inducible factor 1 (HIF-1) mediated signalling which further can prompt several downstream effects [77]. It has been observed that there exist a strong association between hypoxia, endothelial dysfunction and thrombus formation. Vascular response to hypoxia is regulated mainly by HIFs which include several target factors for the regulation of thrombus formation [78]. In fact, the onset of hypoxia turns on phosphatidylinositol-3 kinase/protein kinase B/the mammalian target of rapamycin (PI3K/Akt/mTOR) signalling axis which influences on the activation of HIFs. HIF-1 is a heterodimeric DNA-binding protein which comprises of regulatory $\alpha$-subunit (HIF-1 $\alpha$ ) and a constitutively expressed $\beta$-subunit (HIF-1 $\beta$ ). The functional active form of transcription factor, HIF-1 is achieved by binding of HIF-1 $\alpha$ with subunit HIF-1 $\beta$ in the nucleus and recruiting $\mathrm{p} 300 / \mathrm{CBP}$ acetyltransferases. This complex trigger several target genes by binding to their hypoxia response elements (HRE), which is located within or near around the promoter region of HIF-1 target genes. The accumulation of active complex of HIF- $1 \alpha$, HIF-1 $\beta$ and p300/CBP acetyltransferases in the nucleus causes transcriptional upregulation of HIF-1 which can directly target the process of blood clotting [79]. Particularly, targets of activated HIF-1 regulate prothrombotic factor, TF which favours the formation of stabilized fibrin clot and eventually thrombus generation [80]. Hypoxia may also lead to a concomitant decrease in levels of thrombomodulin activity and protein $\mathrm{S}$ which suggests an increased risk for the consequences of thrombosis $[81,82]$. In addition, hypoxia also suppresses fibrinolytic system by enhancing PAI-1 expression as well as repressing plasminogen activators [83].

Another mechanistic approach for thrombosis caused by hypoxia and HIFs activation is the increased formation of neutrophil extracellular traps (NETs) which are DNA fibres comprises of histones and antimicrobial proteins mediated via peptidylarginine deiminase 4 (PAD4)-regulated histone citrullination. NETs are embedded in the vasculature and have been reported to impact blood clotting by recruiting red blood cells, promoting fibrin deposition, and inducing a red thrombus [84, 85].

Besides this, HIF activation stimulates the expression of hypoxia-inducible adhesive integrins of endothelial cells responsible for stimulating thrombus formation. With the fact that hypoxia harbours an increased endothelial adhesion to fibrinogen via integrin $\alpha \mathrm{V} \beta 3$ and endothelial cell-cell interactions via $\alpha \mathrm{V} \beta 3$ and $\alpha \mathrm{V} \beta 5$ [86, 87]. The endothelial adhesion to fibrinogen facilitates platelet activation and aggregation, essential for the thrombus formation [88].

Earlier studies have also revealed an alternative strategy of coagulation development during hypoxia by Toll-like receptors 3 (TLR3) mediated $\mathrm{NF}-\kappa \mathrm{B} / \mathrm{AP}-1$ signalling in endothelial cells in response to the viral infections [89]. Hypobaric hypoxia mediates TF activation and deposition of fibrin via TLR3 signalling [76]. In fact, hypoxic conditions can lead to TLR3 activation by extracellular RNA (eRNA) which further induces TLR3/ TIR-domain-containing adapter-inducing interferon- $\beta$ (TLR3/TRIF) signalling as well as TLR3/tumor necrosis factor receptor (TNFR)-associated factor 6/ TGF- $\beta$-activated kinase (TLR3/ TRAF6/ TAK) signalling axis for NF- $\kappa$ B and AP-1 induction respectively. Notably, stimulation of $\mathrm{NF}-\kappa \mathrm{B}$ and AP-1 prompt monocyte infiltration, TF expression and hypercoagulation [76, 90, 91].

As a result, it is thought that SARS-CoV-2 can also exploit above discussed pathways which are accountable for Covid-19 infection mediated thrombosis under hypoxic conditions. Henceforth, a wide analysis of mechanisms associated with hypoxia induced thrombotic events during SARS-CoV-2 infection is urgently required in order to alleviate thrombogenic effects during infection by targeting specific molecules.

\section{Effect of Angiogenesis Induced Coagulation during SARS-CoV-2 Infection}

It is well documented that viruses may regulate an angiogenic microenvironment via direct or indirect manner through several ways such as by affecting the synthesis of viral chemokines, growth factors and/or receptors, activation of blood vessels, modulation of activity of cellular proteins as well as induction of a local or systemic inflammatory response. Besides this, viruses generally affect frequent signalling pathways related to angiogenesis which further lead to variations in endothelial cell proliferation, migration and vascular permeability. Importantly, vascular endothelial growth factor (VEGF) is major inducer of angiogenesis involved in mediating vascular remodeling, proliferation and differentiation of endothelial cells as well as vascular leakage and permeability. Importantly, VEGF appears to be an important player in the pathogenesis of many viral diseases [92]. In consistent with above mentioned findings, high levels of serum VEGF levels have been reported in patients infected with SARSCoV-2 in comparison to the healthy controls [73, 93]. The concentrations of VEGF were constantly higher in both ICU and non-ICU Covid-19 patients as compared to controls. VEGF-D has been also identified as a potential marker for the severity of Covid-19 infection [95]. Clinical observations have indicated an interconnection between angiogenic and coagulation pathways [96, 97]. The authors have perceived that elevated VEGF levels might be significantly connected to the storm of blood clots in Covid-19 patients [95]. Moreover, histopathological analysis of 
the pulmonary vessels has showed prevalent thrombosis with microangiopathy in patients with Covid-19 disease [98]. Fundamentally, VEGF, a potent angiogenic factor plays a crucial role in the maintenance and protection of endothelial cells. VEGF acts as an indirect pro-coagulant which activates endothelial cells to become prothrombotic via binding to cell surface receptors, known as vascular endothelial growth factor receptor (VEGFR). There are diverse pathways including phosphoinositide-3-kinases/ phospho-protein kinase B (PI3K/AKT/PKB), rat sarcoma/ rapidly accelerated fibrosarcoma/mitogen-activated protein kinase kinase/phospho-extracellular signal-regulated kinases (RAS/RAF/MEK/ERK) and p38 mitogen-activated protein kinase (MAPK) stimulated by VEGF responsible for endothelial cells survival, proliferation and migration which causes an induction of pro-coagulant factors in endothelial cells (Fig. 4) [99].

Of course, VEGF is capable of upregulating TF expression which is a glycoprotein expressed by endothelial cells [100]. Earlier studies in support to this contention have reported VEGF may affect the homeostasis of thrombotic process by stimulating the expression of $\mathrm{TF}$ in endothelial cells via the formation of the TF-factor VIIa complex which initiates extrinsic coagulation cascade and generate thrombin $[101,102]$. Of particular note, VEGF may also act as an indirect procoagulant by mediating vascular hyperpermeability which results in leakage of plasma proteins such as prothrombin and fibrinogen into the extracellular matrix [103]. Subsequently, the conversion of prothrombin into thrombin is followed by platelet adhesion and activation as well as production of fibrin from fibrinogen. Finally, the antithrombotic surface of the vasculature will transform into a prothrombotic one, causing the synthesis of stabilized thrombus. Earlier observations have demonstrated an essential role of VEGF in the pathogenesis of acute lung injury (ALI) and ARDS through its characteristics to augment vascular permeability $[103,104]$.

Therefore, it is of great significance to develop VEGF inhibitors which may provide therapeutic strategies to treat Covid-19 patients effectively. Thus, there is an urgent need to unravel mechanistic pathways at molecular level in order to verify the role of VEGF in SARS-CoV-2 mediated coagulatory events.

\section{The Integrated Molecular Insights of Mechanistic Pathways Including Hypoxia, Inflammation, Apoptosis and Angiogenesis during SARS-CoV-2 Mediated Thrombosis}

Regarding to the SARS-CoV-2 modulation effect on thrombosis, it has been considered that several coordinated signalling cascades might be dependable for the activation
4Fig. 3 The hypothetical explanation of crucial mechanism for SARS-CoV-2 infection supported hypoxia which is accountable for the induction of coagulation cascade - a Due to SARS-CoV-2 infection in the alveoli of lungs, the phenomenon of oxygen exchange becomes disturbed due to deposition of proteinaceous liquid and fluid in the alveoli and interstitial space respectively and the capillaries become leaky. The resulting condition causes the deprivation of an adequate oxygen supply at the tissue level, generally known as hypoxia, b. the alveolar hypoxia signal is propagated retrogradely along the vascular endothelium and thereby also conveys its damaging effects on vasculature directly by activation of varied signalling cascades, c. In the endothelial cell, hyoxia as a stress signal induces major molecular sensors, mainly HIF-1 by activating PI3K/ AKT/mTOR pathway which subsequently causes recruitment of HIF$1 \alpha$ and $\beta$ in complex with CBP and p300 transcriptional coactivators to the nucleus, d. Further, HIF-1 $\alpha$ and $\beta$ in complex with CBP and p300 binds to the region of HRE and thereby enhance the gene expression of HIF-1, e. the activated HIF-1 in the endothelial cells mediates TLR3 signalling through eRNAs as ligands which causes the nuclear translocation of transcription factors, namely, NF- $\kappa \mathrm{B}$ and AP-1, e. the stimulation of TLR3/TRIF signalling pathway causes the activation of NF- $\kappa \mathrm{B}$, f. Consecutively, TLR3/TRAF6/TAK signalling cascade also supports AP-1 induction, g. All together, these signalling mechanisms may affect coagulation cascade, for example, HIF-1 prompts neutrophil activation which in turn, form NETs via PAD4mediated histone citrullination responsible for inducing a strong coagulatory response, h. HIF-1 augments endothelial adhesion to fibrinogen via integrins which induces platelet activation and aggregation, essential for thrombosis, i. Moreover, activated HIF-1 upregulates the expression of TF and thereby, leads to TF dependent coagulation pathway. At the same time, HIF- $1 \alpha$ also inhibits thrombomodulin-protein $\mathrm{C}$, an anticoagulant system in addition to plasminogen activator of fibrinolysis. Subsequently, this contributes to enhance the pro-coagulant activity of endothelial cells, j. Likewise, HIF-1 induced both NF- $\kappa \mathrm{B}$ and AP-1 also facilitates TF dependent (extrinsic) coagulation pathway dependable for clot formation. The dashed arrow $\left(---\rightarrow^{-}\right)$designates mechanistic pathway undergo through numerous steps and solid arrow ( $\longrightarrow$ ) specify common transformations from one active component to another. Green arrow ( $\longrightarrow$ ) describes activation whereas red blunt arrow (ـ ) indicates inhibition. Abbreviations- SARS-CoV-2severe acute respiratory syndrome coronavirus $2, \mathrm{NF}-\kappa \mathrm{B}-$ nuclear factor- kappa B, HIFs- hypoxia inducible factors, HIFs- $\alpha$ and $\beta$ hypoxia inducible factors $\alpha$ and $\beta$, PI3K-phosphoinositide 3-kinases, AKT - protein kinase $\mathrm{B}$, mTOR- The mammalian target of rapamycin, $\mathrm{CBP}-\mathrm{CREB}$ binding protein, p300- E1A binding protein 300, HRE- hypoxia response element, TLR3- toll like receptors 3, eRNAs- extracellular RNAs, AP-1- activator protein 1, TRIF- TIR-domain-containing adapter-inducing interferon- $\beta$, TRAF6- Tumor necrosis factor receptor-associated factor 6 , TAKTransforming growth factor $\beta$ (TGF $\beta$ )-activated kinase, NETsneutrophil extracellular traps, PAD4- peptidylarginine deiminase 4, $\mathrm{TF}$ - tissue factor

of coagulation cascade which are highly complex and also interconnected to each other. Thus, it has been speculated that hypoxia may act a key feature of the complete framework which can perpetuate distinct cellular signaling pathways related to inflammation, apoptosis and angiogenesis during SARS-CoV-2 infection and subsequently, 


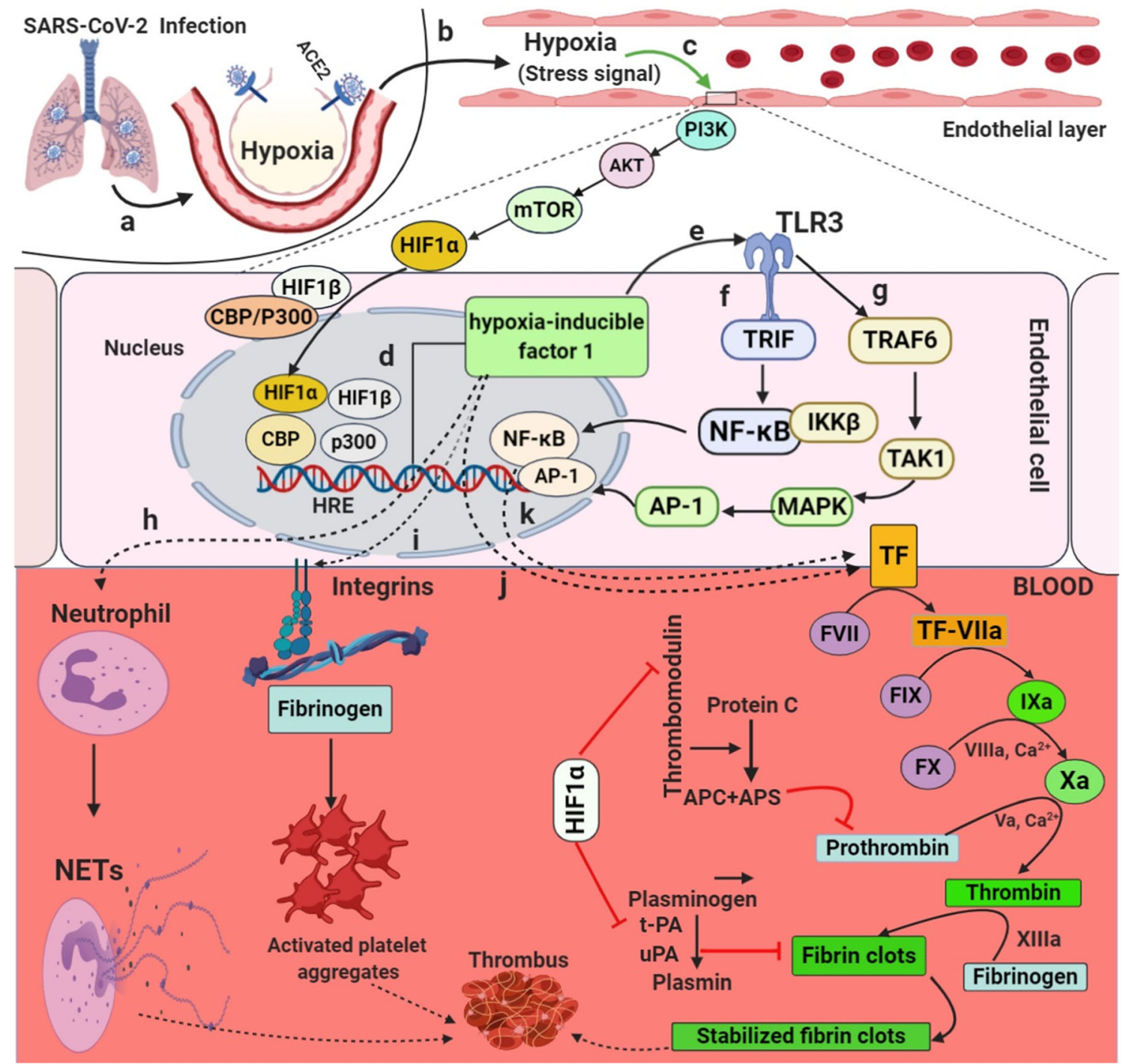

these diverse stimuli can further assemble at a convergence point of the blood clotting cascade (Fig. 5).

A growing body of evidence has indicated a significant interaction between hypoxia (HIF-1) and inflammatory (NF- $\kappa \mathrm{B})$ signalling. Both inflammation and hypoxia are associated to each other at the molecular level. Essentially, both hypoxia (HIFs) and inflammation $(\mathrm{NF}-\kappa \mathrm{B})$ share several common stimuli, regulators and target genes [105]. In fact, hypoxia activates NF- $\mathrm{KB}$ through IKK $\beta$ activation via suppressing the activity of prolyl hydroxylase 1 (PHD1) [106]. Under latent conditions, NF- $\mathrm{KB}$ is predominantly present with its co-repressor molecule IкB in the the cytosolic compartment. On the other hand, oxygen deficit conditions elicit $\mathrm{I} \kappa \mathrm{B} \alpha$ phosphorylation at serine 32 and serine 36, followed by ubiquitination and thereafter degradation proteolytically by the $26 \mathrm{~S}$ proteosome. Subsequently, the nuclear localisation sequence of NF- $\kappa \mathrm{B}$ is then exposed and free to translocate and accumulate in the nucleus. Thereafter, it becomes transcriptionally active by binding to specific $\kappa \mathrm{B}$ sites within the promoter regions of its target genes [107]. As discussed earlier, NF- $\kappa B$ is a fundamental mediator of inflammation and, thus primarily involved in the molecular links between inflammatory and thrombotic processes. Interestingly, there are number of target genes induced by NF- $\mathrm{KB}$ activation including inflammatory genes (TNF- $\alpha$, IL-1, IL-6, IL-8, macrophage inflammatory protein 1 alpha, methyl-accepting chemotaxis protein), cell surface adhesion molecules (E-selectin, VCAM 1, ICAM 1) and several clotting factors (TF, factor VIII, PAI-1) involved in the cascade of both inflammation and coagulation [53-55, 57, 65].

On the other hand, onset of hypoxia can also execute the process of apoptosis. In response to hypoxia, an intricate balance occurs between several factors that can impact on the process of apoptosis directly or indirectly. The chief regulator of the hypoxia response is hypoxia inducible 


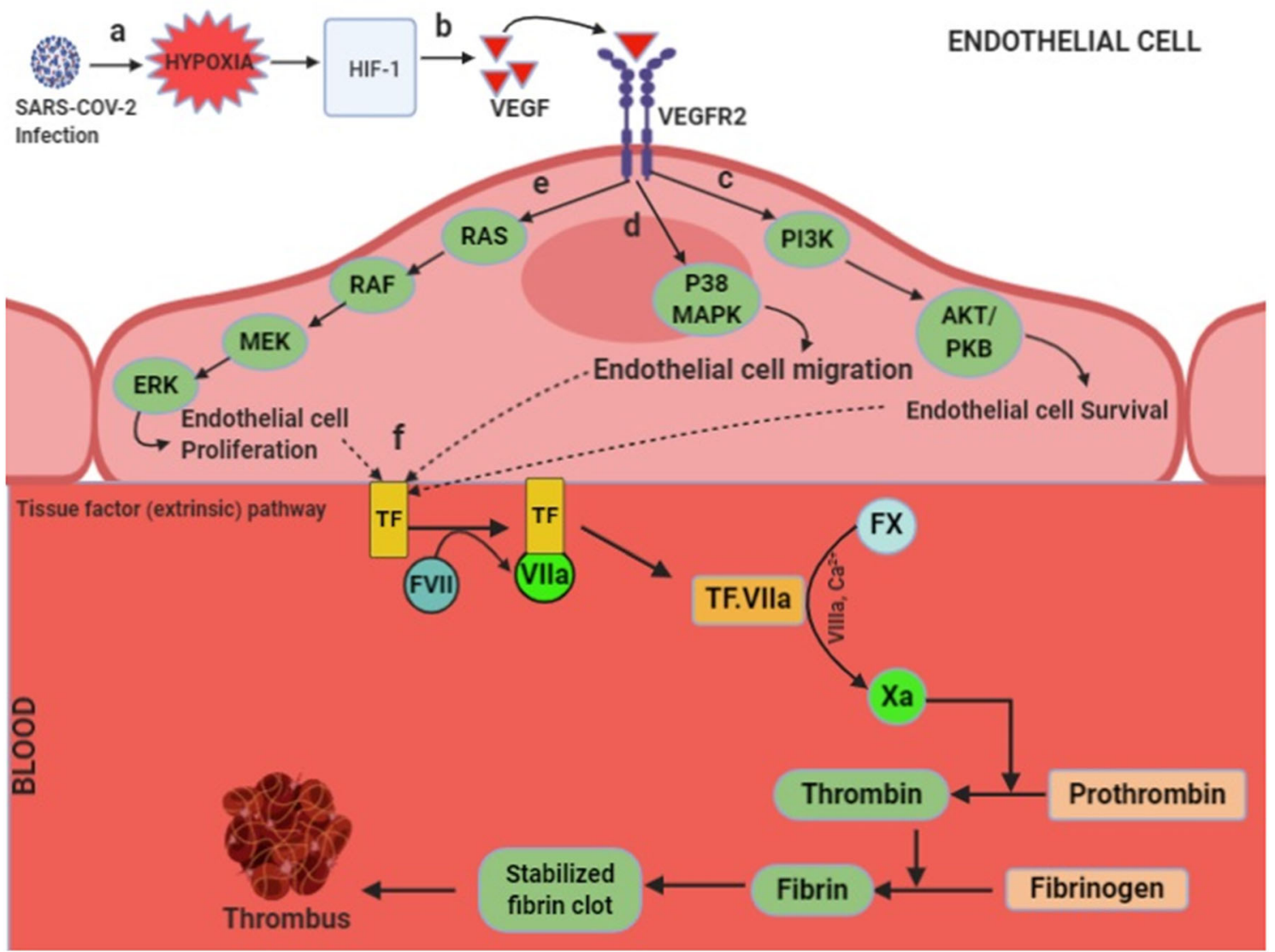

Fig. 4 Possible representation illustrating fundamental mechanism of angiogenesis activated coagulation pathway in Covid-19 disease- a. SARS-CoV-2 infection causes hypoxia which activates major molecular sensor, mainly hypoxia induced genes (HIFs), b. HIF-1 is known to increase VEGF levels which in turn, activate VEGF receptor 2 (VEGFR2) on endothelial cells in an autocrine and paracrine manner. The activated VEGFR2 further supports endothelial cell survival, proliferation and migration via varied signalling pathways, c. Infact, VEGF-VEGFR2 induction carries out PI3K/AKT/PKB signalling for the survival of endothelial cells. d. Further, VEGFR2 activation promotes endothelial cell migration pathway by mediating P38/MAPK signalling mechanism, e. Additionally, VEGF-VEGFR2 favors Ras/Raf/Mek/ Erk signalling for the proliferation of endothelial cells, f. Interestingly, these signalling mechanisms promote $\mathrm{TF}$ dependent coagulation pathway by stimulating the formation of TF-VIIa complex which generates active factor Xa through the involvement of VIIIa and $\mathrm{Ca}^{2+}$. The active

factor-1 (HIF-1) that can bind to hypoxia response element (HRE; 5'-RCGTG-3') sequences in the promoter regions of HIF-1 target genes to modulate the gene expression of several adaptive pathways including apoptosis [108, 109]. HIF-1 has been reported to stimulate apoptotic pathways through diverse mechanisms. One mechanistic approach occurs through hyperpermeability of inner mitochondrial membrane causing the release of cytochrome $\mathrm{C}$ into the cytosol. This results in the activation of apoptotic protease activating factor 1 (Apaf-1) followed by formation of an oligomeric apoptosome which stimulates the caspase cascade that commits the cell to apoptosis. Another factor, $\mathrm{Xa}$ is required for the synthesis of cross-linked fibrin clots, necessary for the thrombus synthesis. The dashed arrow $(----\rightarrow)$ illustrates respective mechanism occurs through a number of steps and solid arrow ( $\longrightarrow$ ) denotes universal switch of signal from one active component to another component. Green arrow $(\longrightarrow)$ describes activation whereas red blunt arrow (_ $)$ describes inhibition. Abbreviations- Covid-19- coronavirus disease 2019, SARS$\mathrm{CoV}-2$ - severe acute respiratory syndrome coronavirus 2, VEGFvascular endothelial growth factor, VEGFR2- vascular endothelial growth factor receptor 2, PI3K- phosphoinositide-3-kinases, AKT/PKBprotein kinase $\mathrm{B}, \mathrm{P} 38 \mathrm{MAPK}-\mathrm{p} 38$ mitogen-activated protein kinases, Ras- rat sarcoma, Raf- rapidly accelerated fibrosarcoma, Mek- mitogenactivated protein kinase kinase, Erk- extracellular signal-regulated kinases, $\mathrm{TF}-$ tissue factor, $\mathrm{Ca}^{2+}-$ calcium ions

mechanism carried out by hypoxia for initiation of apoptosis is the activation of proapoptotic protein, B-cell lymphoma 2 (Bcl-2) adenovirus E1B interacting protein 3 (BNIP3) in endothelial cells which triggers cell death by inhibiting the antiapoptotic effect of B-cell lymphoma 2 (Bcl-2) and B-cell lymphoma xL (Bcl-xL) or by stabilising wild-type p53 [110]. Alternatively, third mechanism involves stimulation of c-Jun $\mathrm{NH}_{2}$-terminal kinase/stress activated protein kinase (JNK/SAPK) signalling pathway which initiates apoptotic cascade via an unknown mechanism [111]. Most importantly, it has been already mentioned that induction of apoptosis causes externalization of 


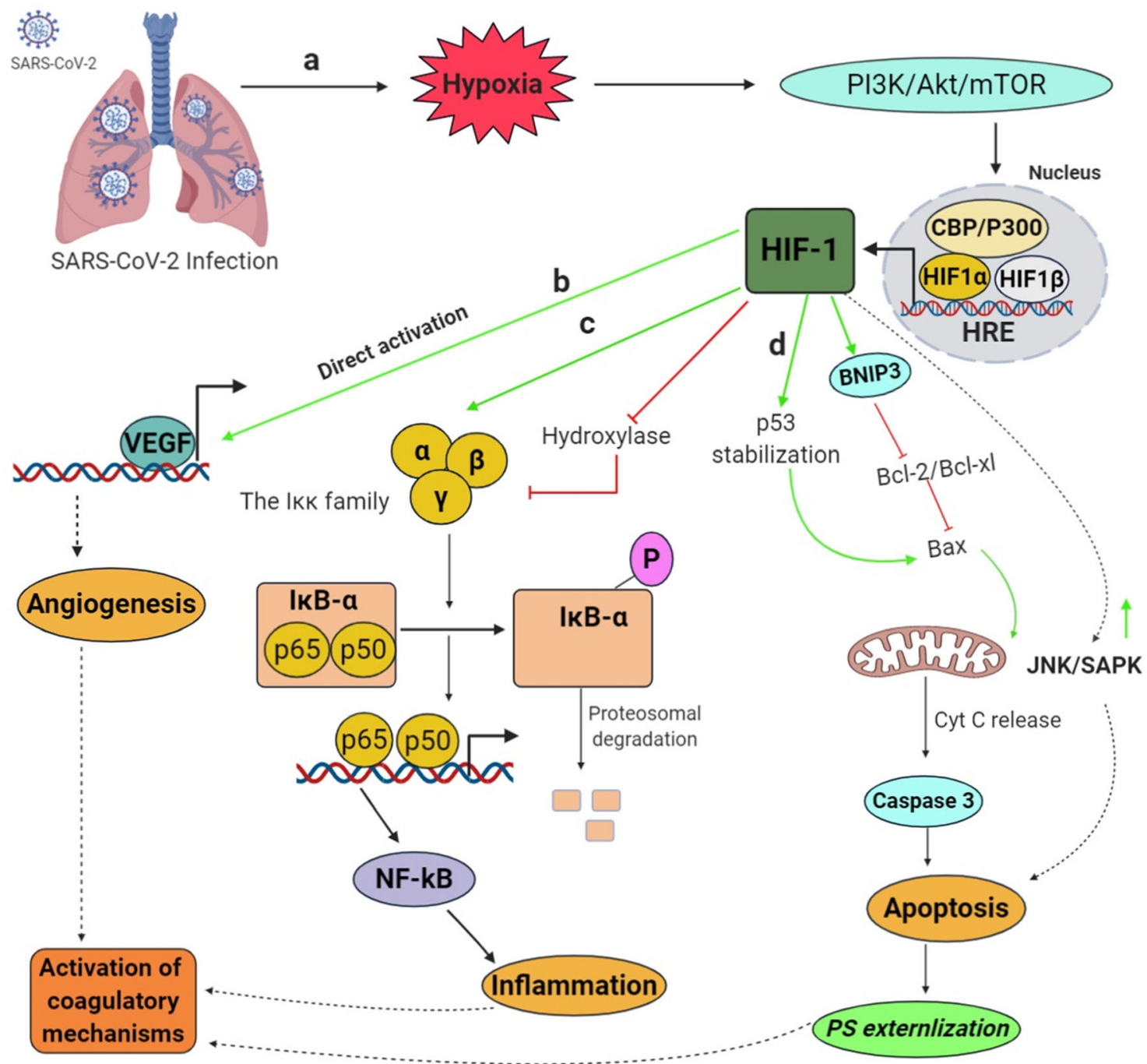

Fig. 5 The overall hypothetical outline of integrated approach of distinct signalling axis for the stimulation of coagulatory mechanism during Covid-19 infection a. The infection of SARS-CoV-2 in the lungs generates a condition of hypoxia followed by the activation of $\mathrm{PI} 3 \mathrm{~K} / \mathrm{Akt} / \mathrm{mTOR}$ signallingwhich ultimately stimulates HIF-1 by forming a complex of HIF- $1 \alpha$ and HIF-1 $\beta$ in combination with transactivators including $\mathrm{CBP}$ and P300, b. The activated HIF-1 complex turns on the direct expression of VEGF, essential for the process of angiogenesis, c. HIF-1 also triggers expression of NF- $\kappa \mathrm{B}$, a transcription factor by activating of IKK complex (IKK $\alpha$, IKK $\beta$ and $\operatorname{IKK} \gamma)$ to phosphorylate the inhibitor of the classical pathway $(\mathrm{I} \kappa \mathrm{B} \alpha)$, resulting degradation by its proteasomes. The transcriptionally active classical NF- $\kappa B$ heterodimer (p50:p65) then gets free to enter the nucleus and affect transcription of inflammatory genes, d. Simultaneously, HIF-1 also enhances apoptotic response by facilitating mitochondria to release cytochrome $\mathrm{C}$ and activates caspase 3 . Likewise, HIF-1 can activate BNIP3 which binds Bcl-2/Bcl-xl and activates proapoptotic protein, Bax. HIF-1 also causes the stabilization of $\mathrm{p} 53$, required for apoptosis. JNK/SAPK signalling activated by HIF-1 can also initiate apoptotic cascade through an unknown mechanism. These signalling activation by HIF-1 can trigger the process of apoptosis, followd by PS externalization, Collectively, hypoxia induced mechanisms including inflammation, angiogenesis and apoptosis can further direct to the establishment of thrombotic cascades. The dashed arrow $(---\rightarrow)$ ) indicates mechanistic pathway undergo through numerous steps and solid arrow $\longrightarrow$ ) illustrates transfer of signal from one active compound to another compound. Green arrow ( $\longrightarrow$ ) shows activation whereas red blunt arrow ( $\_$) depicts inhibition. Abbreviations- Covid 19coronavirus disease 19, SARS-CoV-2- severe acute respiratory syndrome coronavirus 2 , NF- $\kappa \mathrm{B}-$ nuclear factor- kappa $\mathrm{B}$, IKKinhibitor of nuclear factor- kappa-B kinase, IKK $\alpha$ - inhibitor of nuclear factor- kappaB kinase subunit alpha, IKK $\beta$ - inhibitor of nuclear factor- kappa-B kinase subunit beta, IKK $\gamma$ - inhibitor of nuclear factor- kappaB kinase subunit gamma, HIFs- hypoxia inducible factors, HIFs- $\alpha$ and $\beta$ - hypoxia inducible factors $\alpha$ and $\beta$, PI3K- phosphoinositide- 3-kinases, AKT/PKB - protein kinase B, mTOR - the mammalian target of rapamycin, CBP- CREB binding protein, p300- E1A binding protein 300, VEGF- vascular endothelial growth factor, BNIP3- B-cell lymphoma 2 (Bcl-2) adenovirus E1B interacting protein 3, Bcl-2- B-cell lymphoma 2, Bcl-xl- B-cell lymphoma $\mathrm{xl}$, JNK- c-Jun $\mathrm{NH}_{2}$-terminal kinase, SAPK- stress activated protein kinase, PS- phosphatidylserine 
PS on outer leaflet of biological cell membrane which is coupled to activation of the blood coagulation cascade [45].

Accumulating evidences have also suggested the strong connection between hypoxia and angiogenesis. Hypoxia directly induces the expression of genes related to angiogenesis such as VEGF. HIF-1 mediated signalling is a primary regulator of VEGF during hypoxic conditions [112]. As mentioned above, hypoxia suppresses the activity of prolyl hydroxylases followed by stabilization and dimerization of HIF-1 $\alpha$ with HIF-1 $\beta$ which finally translocates to the nucleus. Thereafter, this complex binds hypoxia response elements (HREs) within the promoters of target genes, for example, VEGF and mediates its expression. Further, VEGF family members interrelate with their receptors (VEGFR-1,-2,-3) which lead to different biological consequences including induction of blood clotting process. It has been discussed that VEGF, a chief stimulator of angiogenesis can activate endothelial cells to become prothrombotic by increasing $\mathrm{TF}$ expression on their membranes for the activation of the coagulation process [100-102].

Collectively, it has been hypothesized that hypoxia can act as a main culprit for initiating overall thrombotic events during SARS-CoV-2 infection by involving complex agenda of diverse signalling axis related to apoptosis, inflammation and angiogenesis. However, by understanding underlying mechanistic approach for the activation of blood clotting cascade, where the pathways can be regulated, as well as the circumstances of the stimuli, these studies could provide exceptionally useful information that eventually should be used to unmask novel therapeutic schemes against during Covid-19 mediated thrombosis.

\section{Future Perspectives}

Owing to the present pandemic scenario, it has become more challenging for health care settings to develop any therapeutic molecules to treat Covid-19 disease, yet due to insufficient data on disease pathogenesis. Notwithstanding, scientists and clinicians are critically making all efforts to understand about SARS-CoV-2 virus as well as the management of its Covid-19 disease. Recent studies have revealed that SARS-CoV-2 infection is associated with coagulopathy of varying degrees as a result of the profound endothelial activation/damage. Additionally, the pathology of Covid-19 is further exacerbated with the progression of thrombosis. With this concern, in this review, innovative analysis of distinct downstream molecular signalling mechanisms related to the manifestations of thrombotic events during Covid-19 disease has been delineated. Thus, it has been hypothesized that, during
SARS-CoV-2 infection, onset of hypoxia may acts as a key player driving many molecular mechanisms including apoptosis, inflammation and angiogenesis which ultimately underpin pathological thrombosis. Fascinatingly, it has been believed that any direct or indirect inhibition of underlying molecular pathways including hypoxia, inflammatory, apoptotic and angiogenic may alleviate the progression of thrombosis during SARS-CoV-2 infection. Though it is only a hypothetical approach, however, an extensive research is needed to understand the role of abovementioned diverse molecular signalling pathways in SARS-CoV-2 mediated coagulopathy which might prevent or mitigate the consequences derived from rapidly spreading SARS-CoV-2 infection and hence, could be beneficial to combat Covid-19 disease.

Acknowledgements We here acknowledge the management of M.M. Institute of Medical Sciences and Research (MMIMSR), Maharishi Markandeshwar University (MMU) Mullana, Ambala, Haryana, India

Author Contributions IR has designed the concept of study and has made figures of the article. AG has written and edited the original draft of manuscript. RP has supervised for final approval of the version to be submitted. PG and AP done revision of article draft critically as well as also reviewed manuscript. SP has done final editing and formal analysis of the article draft.

Funding None.

Declarations

Conflict of interest There is no conflict of interest.

\section{References}

1. WHO. Novel coronavirus: China. 2020. Available from: https:// www.who.int/csr/don/12-january-2020-novel-coronaviruschina/en/.

2. CDC. 2019 Novel coronavirus, Wuhan, China. 2020. Available from: https://www.cdc.gov/coronavirus/2019-nCoV/summary. html.

3. Harenberg J, Favaloro E. COVID-19: progression of disease and intravascular coagulation:present status and future perspectives. Clin Chem Lab Med. 2020;58(7):1029-36.

4. Al-Ani F, Chehade S, Lazo-Langner A. Thrombosis risk associated with Covid-19 infection a scoping review. Thromb Res. 2020;192:152-60.

5. McFadyen JD, Stevens H, Peter K. The emerging threat of (Micro)thrombosis in COVID-19 and its therapeutic implications. Circ Res. 2020;127(4):571-87.

6. Yau JW, Teoh H, Verma S. Endothelial cell control of thrombosis. BMC Cardiovasc Disord. 2015;15:130.

7. Palta S, Saroa R, Palta A. Overview of the coagulation system. Indian J Anaesth. 2014;58(5):515-23.

8. Johari V, Loke C. Brief overview of the coagulation cascade. Dis Mon. 2012;58(8):421-3.

9. Mackow ER, Gorbunova EE, Gavrilovskaya IN. Endothelial cell dysfunction in viral hemorrhage and edema. Front Microbiol. 2014;5:733. 
10. Hensley LE, Geisbert TW. The contribution of the endothelium to the development of coagulation disorders that characterize Ebola hemorrhagic fever in primates. Thromb Haemost. 2005;94:254-61.

11. Jiang Z, Tang X, Xiao R, Jiang L, Chen X. Dengue virus regulates the expression of hemostasis-related molecules in human vein endothelial cells. J Inf Secur. 2007;55:23-8.

12. Friedman HM, Macarak EJ, MacGregor RR, Wolfe J, Kefalides NA. Virus infection of endothelial cells. J Infect Dis. 1981;143(2):266-73.

13. Friedman HM, Wolfe J, Kefalides NA, Macarak EJ. Susceptibility of endothelial cells derived from different blood vessels to common viruses. vitro Cell Dev Biol. 1986;22(7):397-401.

14. van Gorp EC, Suharti C, ten Cate H, Dolmans WM, van der Meer JW, ten Cate JW, Brandjes DP. Review: infectious diseases and coagulation disorders. J Infect Dis. 1999;180:176-86.

15. Geisbert TW, Hensley LE, Jahrling PB, Larsen T, Geisbert JB, Paragas $\mathrm{J}$, et al. Treatment of Ebola virus infection with a recombinant inhibitor of factor VIIa/tissue factor: a study in rhesus monkeys. Lancet. 2003;362:1953-8.

16. Antoniak S, Mackman N. Multiple roles of the coagulation protease cascade during virus infection. Blood. 2014;123:2605-13.

17. Becker RC. Toward understanding the 2019 Coronavirus and its impact on the heart. J Thromb Thrombolysis. 2020;50:33-42.

18. Hoffmann M, Kleine-Weber H, Schroeder S, Krüger N, Herrler T, Erichsen S, et al. SARS-CoV-2 cell entry depends on ACE2 and TMPRSS2 and is blocked by a clinically proven protease inhibitor. Cell. 2020;181:271-80.

19. Hamming I, Timens W, Bulthuis M, Lely A, Navis G, van Goor $\mathrm{H}$. Tissue distribution of ACE2 protein, the functional receptor for SARS coronavirus: a first step in understanding SARS pathogenesis. J Pathol. 2004;203:631-7.

20. Aimes RT, Zijlstra A, Hooper JD, Ogbourne SM, Sit M-L, Fuchs $\mathrm{S}$, et al. Endothelial cell serine proteases expressed during vascular morphogenesis and angiogenesis. Thromb Haemost. 2003;89:561-72.

21. Jeffers SA, Tusell SM, Gillim-Ross L, Hemmila EM, Achenbach JE, Babcock GJ, et al. CD209L (L-SIGN) is a receptor for severe acute respiratory syndrome coronavirus. Proc Natl Acad Sci USA. 2004;101:15748-53.

22. Yu YTC, Chien SC, Chen IY, Lai CT, Tsay YG, Chang SC, et al. Surface vimentin is critical for the cell entry of SARSCoV. J Biomed Sci. 2016;23:1-10.

23. Wang T, Shimizu Y, Wu X, Kelly GT, Xu X, Wang L, et al. Particulate matter disrupts human lung endothelial cell barrier integrity via Rho-dependent pathways. Pulm Circ. 2017;7:617-23.

24. Fattorini D, Regoli F. Role of the chronic air pollution levels in the Covid-19 outbreak risk in Italy. Environ Pollut. 2020;264:114732.

25. Poissy J, Goutay J, Caplan M, Parmentier E, Duburcq T, Lassalle F, et al. Pulmonary Embolism in Patients With COVID-19: Awareness of an Increased Prevalence. Circulation. 2020;142(2):184-6.

26. Al-Samkari H, Karp Leaf RS, Dzik WH, Carlson JCT, Fogerty AE, Waheed A, et al. COVID-19 and coagulation: bleeding and thrombotic manifestations of SARS-CoV-2 infection. Blood. 2020;136(4):489-500.

27. Klok FA, Kruip M, van der Meer NJM, et al. Incidence of thrombotic complications in critically ill ICU patients with COVID-19. Thromb Res. 2020;191:145-7.

28. Tang N, Li D, Wang X, Sun Z. Abnormal coagulation parameters are associated with poor prognosis in patients with novel coronavirus pneumonia. J Thrombosis Haemostasis. 2020;18(4):844-7.
29. Winn RK, Harlan JM. The role of endothelial cell apoptosis in inflammatory and immune diseases. J Thromb Haemost. 2005;3(8):1815-24.

30. Bombeli T, Schwartz BR, Harlan JM. Endothelial cells undergoing apoptosis become proadhesive for nonactivated platelets. Blood. 1999;93:3831-8.

31. Schwartz BR, Karsan A, Bombeli T, Harlan JM. A novel beta 1 integrin-dependent mechanism of leukocyte adherence to apoptotic cells. J Immunol. 1999;162:4842-8.

32. Bombeli T, Karsan A, Tait JF, Harlan JM. Apoptotic vascular endothelial cells become procoagulant. Blood. 1997;89:2429-42.

33. Casciola-Rosen L, Rosen A, Petri M, Schlissel M. Surface blebs on apoptotic cells are sites of enhanced procoagulant activity: implications for coagulation events and antigenic spread in systemic lupus erythematosus. Proc Natl Acad Sci USA. 1996;93:1624-9.

34. Ren Y, Shu T, Wu D, Mu J, Wang C, Huang M, Han Y, Zhang XY, Zhou W, Qiu Y, Zhou X. The ORF3a protein of SARSCoV-2 induces apoptosis in cells. Cell Mol Immunol. 2020;17(8):881-3.

35. Bombeli T, Karsan A, Tait JF, Harlan JM. Apoptotic vascular endothelial cells become procoagulant. Blood. 1997;89(7):2429-42.

36. Varga Z, Flammer AJ, Steiger P, Haberecker M, Andermatt R, Zinkernagel AS, Mehra MR, Schuepbach RA, Ruschitzka F, Moch H. Endothelial cell infection and endotheliitis in COVID19. Lancet. 2020;395(10234):1417-8.

37. Colmenero I, Santonja C, Alonso-Riaño M, Noguera-Morel L, Hernández-Martín A, Andina D, et al. SARS-CoV-2 endothelial infection causes COVID-19 chilblains: histopathological, immunohistochemical and ultrastructural study of seven paediatric cases. Br J Dermatol. 2020;183(4):729-37.

38. Ming Y. Cell pyroptosis, a potential pathogenic mechanism of 2019-nCoV infection. SSRN Electron J. 2020. https://doi.org/10. 2139/ssrn.3527420.

39. Perico L, Benigni A, Casiraghi F, Ng LFP, Renia L, Remuzzi G. Immunity, endothelial injury and complement-induced coagulopathy in COVID-19. Nat Rev Nephrol. 2020. https://doi.org/ 10.1038/s41581-020-00357-4.

40. Rauch A, Dupont A, Goutay J, Caplan M, Staessens S, Moussa $\mathrm{M}$, et al. Lille COVID research network (LICORNE); members of the LICORNE scientific committee: endotheliopathy is induced by plasma from critically Ill patients and associated with organ failure in severe COVID-19. Circulation. 2020;142(19):1881-4.

41. Segawa K, Kurata S, Yanagihashi Y, Brummelkamp TR, Matsuda F, Nagata S. Caspase-mediated cleavage of phospholipid flippase for apoptotic phosphatidylserine exposure. Science. 2014;344(6188):1164-8.

42. Connor J, Bucana C, Fidler IJ, Schroit AJ. Differentiation-dependent expression of phosphatidylserine in mammalian plasma membranes: quantitative assessment of outer-leaflet lipid by prothrombinase complex formation. Proc Natl Acad Sci USA. 1989;86(9):3184-8.

43. Gao C, Xie R, Yu C, Ma R, Dong W, Meng H, et al. Thrombotic role of blood and endothelial cells in uremia through phosphatidylserine exposure and microparticle release. PLoS ONE. 2015;10(11):e0142835.

44. Rao LV, Pendurthi UR. Regulation of tissue factor coagulant activity on cell surfaces. J Thromb Haemost. 2012;10:2242-53.

45. Greeno EW, Bach RR, Moldow CF. Apoptosis is associated with increased cell surface tissue factor procoagulant activity. Lab Invest. 1996;75:281-9.

46. Ansari SA, Pendurthi UR, Sen P, Rao LVM. The role of putative phosphatidylserine-interactive residues of tissue factor on its 
coagulant activity at the cell surface. PLoS ONE. 2016;11(6):e0158377.

47. Shantsila E, Montoro-García S, Gallego P, Lip GY. Circulating microparticles: challenges and perspectives of flow cytometric assessment. Thromb Haemost. 2014;111(6):1009-14.

48. Lacroix R, Dignat-George F. Microparticles as a circulating source of procoagulant and fibrinolytic activities in the circulation. Thromb Res. 2012;129(2):27-9.

49. Azkur AK, Akdis M, Azkur D, Sokolowska M, van de Veen W, Brüggen $\mathrm{MC}$, et al. Immune response to SARS-CoV-2 and mechanisms of immunopathological changes in COVID-19. Allergy. 2020;75(7):1564-81.

50. Ye Q, Wang B, Mao J. The pathogenesis and treatment of the 'Cytokine Storm' in COVID-19. J Infect. 2020;80(6):607-13.

51. Mussbacher M, Salzmann M, Brostjan C, Hoesel B, Schoergenhofer $\mathrm{C}$, Datler $\mathrm{H}$, et al. Cell type-specific roles of NF- $\kappa \mathrm{B}$ linking inflammation and thrombosis. Front Immunol. 2019;10:85.

52. Zheng GJ, Sun Q, Li YP. Inflammation, endothelium, coagulation in sepsis. Zhongguo Wei Zhong Bing Ji Jiu Yi Xue. 2009;21(9):573-6.

53. Eilertsen K-E, Østerud B. Tissue factor: (patho) physiology and cellular biology. Blood Coagul Fibrinolysis. 2004;15:521-38.

54. Darbousset R, Thomas GM, Mezouar S, Frere C, Bonier R, Mackman N, et al. Tissue factor-positive neutrophils bind to injured endothelial wall and initiate thrombus formation. Blood. 2012;120:2133-43.

55. McDonald B, Davis RP, Kim SJ, Tse M, Esmon CT, Kolaczkowska E, et al. Platelets and neutrophil extracellular traps collaborate to promote intravascular coagulation during sepsis in mice. Blood. 2017;129:1357-67.

56. Middleton EA, He XY, Denorme F, Campbell RA, Ng D, Salvatore SP, et al. Neutrophil extracellular traps contribute to immunothrombosis in COVID-19 acute respiratory distress syndrome. Blood. 2020;136(10):1169-79.

57. Joyce DE, Gelbert L, Ciaccia A, DeFoff B, Grinnell BW. Gene expression profile of antithrombotic protein $\mathrm{C}$ defines new mechanisms modulating inflammation and apoptosis. J Biol Chem. 2001;276:11199-203.

58. Rahman A, Anwar KN, True AL, Malik AB. Thrombin-induced p65 homodimer binding to downstream NF-kappa B site of the promoter mediates endothelial ICAM-1 expression and neutrophil adhesion. J Immunol. 1999;162:5466-76.

59. Sugama Y, Tiruppathi C, offakidevi K, Andersen TT, Fenton JWII, Malik AB. Thrombin-induced expression of endothelial P-selectin and intercellular adhesion molecule-1: a mechanism for stabilizing neutrophil adhesion. $J$ Cell Biol. 1992;119:935-44.

60. Xue J, Thippegowda PB, Hu G, Bachmaier K, Christman JW, Malik AB, et al. NF-kappa B regulates thrombin-induced ICAM-1 gene expression in cooperation with NFAT by binding to the intronic NF-kappaB site in the ICAM-1 gene. Physiol Genom. 2009;38:42-53.

61. Schouten M, Wiersinga WJ, Levi M, Van Der Poll T. Inflammation, endothelium and coagulation in sepsis. J Leukoc Biol. 2008;83(3):536-45.

62. Anrather D, Millan MT, Palmetshofer A, et al. Thrombin activates nuclear factor-kappaB and potentiates endothelial cell activation by TNF. J Immunol. 1997;159(11):5620-8.

63. Levi M, Schultz M, van der Poll T. Sepsis and thrombosis. Semin Thromb Hemost. 2013;39:559-66.

64. Liu SF, Malik AB. NF-kappa B activation as a pathological mechanism of septic shock and inflammation. Am J Physiol Lung Cell Mol Physiol. 2006;290:622-45.

65. Mutlu GM, Green D, Bellmeyer A, Baker CM, Burgess Z, Rajamannan N, et al. Ambient particulate matter accelerates coagulation via an IL-6-dependent pathway. J Clin Investig. 2007;117:2952-61.

66. Branchford BR, Carpenter SL. The role of inflammation in venous thromboembolism. Front Pediatr. 2018;6:142.

67. Desai TR, Leeper NJ, Hynes KL, Gewertz BL. Interleukin-6 causes endothelial barrier dysfunction via the protein kinase $\mathrm{C}$ pathway. J Surg Res. 2002;104:118-23.

68. Nawroth PP, Stern DM. Modulation of endothelial cell hemostatic properties by tumor necrosis factor. J Exp Med. 1986;163:740-5.

69. Nawroth PP, Handley DA, Esmon CT, Stern DM. Interleukin 1 induces endothelial cell procoagulant while suppressing cellsurface anticoagulant activity. Proc Natl Acad Sci USA. 1986;83:3460-4.

70. Tay MZ, Poh CM, Rénia L, MacAry PA, Ng LFP. The trinity of COVID-19: immunity, inflammation and intervention. Nat Rev Immunol. 2020. https://doi.org/10.1038/s41577-020-0311-8.

71. Witkowski M, Landmesser U, Rauch U. Tissue factor as a link between inflammation and coagulation. Trends Cardiovasc Med. 2016;26(4):297-303.

72. Dong J, Fujii S, Imagawa S, Matsumoto S, Matsushita M, Todo S, et al. IL-1 and IL-6 induce hepatocyte plasminogen activator inhibitor-1 expression through independent signaling pathways converging on C/EBP $\delta$. Am J Physiol Cell Physiol. 2007;292(1):209-15.

73. Costela-Ruiz VJ, Illescas-Montes R, Puerta-Puerta JM, Ruiz C, Melguizo-Rodríguez L. SARS-CoV-2 infection: The role of cytokines in COVID-19 disease. Cytokine Growth Factor Rev. 2020;54:62-75.

74. Tobin MJ, Laghi F, Jubran A. Why COVID-19 Silent Hypoxemia Is Baffling to Physicians. Am J Respir Crit Care Med. 2020;202(3):356-60.

75. Del Turco S, Vianello A, Ragusa R, Caselli C, Basta G. COVID19 and cardiovascular consequences: Is the endothelial dysfunction the hardest challenge? Thromb Res. 2020;196:143-51.

76. Biswas I, Garg I, Singh B, Khan GA. A key role of Toll-like receptor 3 in tissue factor activation through extracellular signal regulated kinase $1 / 2$ pathway in a murine hypoxia model. Blood Cells Mol Dis. 2012;49:92-101.

77. Bracken CP, Whitelaw ML, Peet DJ. The hypoxia-inducible factors: key transcriptional regulators of hypoxic responses. Cell Mol Life Sci. 2003;60(7):1376-93.

78. Evans CE. Hypoxia and HIF activation as a possible link between sepsis and thrombosis. Thromb J. 2019;17:16.

79. Zhang Z, Yao L, Yang J, Wang Z, Du G. PI3K/Akt and HIF-1 signaling pathway in hypoxia-ischemia (Review). Mol Med Rep. 2018;18(4):3547-54.

80. Rong Y, Post DE, Pieper RO, Durden DL, Van Meir EG, Brat DJ. PTEN and hypoxia regulate tissue factor expression and plasma coagulation by glioblastoma. Cancer Res. 2005;65(4):1406-13.

81. Pilli VS, Datta A, Afreen S, Catalano D, Szabo G, Majumder R. Hypoxia downregulates protein $\mathrm{S}$ expression. Blood. 2018;132(4):452-5.

82. Ogawa S, Shreeniwas R, Butura C, Brett J, Stern DM. Modulation of endothelial function by hypoxia: perturbation of barrier and anticoagulant function, and induction of a novel factor $\mathrm{X}$ activator. Adv Exp Med Biol. 1990;281:303-12.

83. Liao H, Hyman MC, Lawrence DA, Pinsky DJ. Molecular regulation of the PAI-1 gene by hypoxia: contributions of Egr-1, HIF-1alpha, and C/EBPalpha. FASEB J. 2007;21(3):935-49.

84. McInturff AM, Cody MJ, Elliott EA, Glenn JW, Rowley JW, Rondina MT, Yost CC. Mammalian target of rapamycin regulates neutrophil extracellular trap formation via induction of hypoxia-inducible factor 1 alpha. Blood. 2012;120:3118-25. 
85. Fuchs TA, Brill A, Duerschmied D, Schatzberg D, Monestier M, Myers DD Jr, Wrobleski SK, Wakefield TW, Hartwig JH, Wagner DD. Extracellular DNA traps promote thrombosis. Proc Natl Acad Sci USA. 2010;107:15880-5.

86. Walton HL, Corjay MH, Mohamed SN, Mousa SA, Santomenna LD, Reilly TM. Hypoxia induces differential expression of the integrin receptors alpha (vbeta3) and alpha (vbeta5) in cultured human endothelial cells. J Cell Biochem. 2000;78:674-80.

87. Niu JX, Zhang WJ, Ye LY, Wu LQ, Zhu GJ, Yang ZH, Grau GE, Lou JN. The role of adhesion molecules, alpha $v$ beta 3 , alpha $v$ beta 5 and their ligands in the tumor cell and endothelial cell adhesion. Eur J Cancer Prev. 2007;16:517-27.

88. Yun SH, Sim EH, Goh RY, Park JI, Han JY. Platelet Activation: The Mechanisms and Potential Biomarkers. Biomed Res Int. 2016;2016:9060143.

89. Jahani M, Dokaneheifard S, Mansouri K. Hypoxia: A key feature of COVID-19 launching activation of HIF-1 and cytokine storm. J Inflamm (Lond). 2020;17:33.

90. Akira S, Takeda K. Toll-like receptor signalling. Nat Rev Immunol. 2004;4(7):499-511.

91. Biswas I, Singh B, Sharma M, Agrawala PK, Khan GA. Extracellular RNA facilitates hypoxia-induced leukocyte adhesion and infiltration in the lung through TLR3-IFN-?-STAT1 signaling pathway. Eur J Immunol. 2015;9:3158-73.

92. Alkharsah KR. VEGF Upregulation in Viral Infections and Its Possible Therapeutic Implications. Int $\mathrm{J}$ Mol Sci. 2018;19(6):1642.

93. Yazihan N, Tanacan A, Erol SA, Anuk AT, Sinaci S, Biriken D, Keskin HL, Moraloglu OT, Sahin D. Comparison of VEGF-A values between pregnant women with COVID-19 and healthy pregnancies and its association with composite adverse outcomes. J Med Virol. 2020. https://doi.org/10.1002/jmv.26631.

94. Huang C, Wang Y, Li X, Ren L, Zhao J, Hu Y, et al. Clinical features of patients infected with 2019 novel coronavirus in Wuhan. China Lancet. 2020;395(10223):497-506.

95. Kong Y, Han J, Wu X, Zeng H, Liu J, Zhang H. VEGF-D: a novel biomarker for detection of COVID-19 progression. Crit Care. 2020;24(1):373.

96. Kakkar AK, DeRuvo N, Chinswangwatanakul V, Tebutt S, Williamson RCN. Extrinsic-pathway activation in cancer with high factor VIIa and tissue factor. Lancet. 1995;346:1004-5.

97. Craft PS, Harris AL. Clinical prognostic significance of tumour angiogenesis. Ann Oncol. 1994;5:305-11.

98. Recalde-Zamacona B, García-Tobar L, Argueta A, Álvarez L, De Andrea CE, Fernández Alonso M, et al. Histopathological findings in fatal COVID-19 severe acute respiratory syndrome: preliminary experience from a series of 10 Spanish patients. Thorax. 2020;75(12):1116-8.
99. Holmes K, Roberts OL, Thomas AM, Cross MJ. Vascular endothelial growth factor receptor-2: structure, function, intracellular signalling and therapeutic inhibition. Cell Signal. 2007;19:2003-12.

100. Zucker S, Mirza H, Conner CE, Lorenz AF, Drews MH, Bahou WF, Jesty J. Vascular endothelial growth factor induces tissue factor and matrix metalloproteinase production in endothelial cells: conversion of prothrombin to thrombin results in progelatinase-A activation and cell proliferation. Int $\mathrm{J}$ Cancer. 1998;75:780-6.

101. Zhang Y, Deng Y, Luther T, Muller M, Ziegler R, Waldherr R, Stern DM, Nawroth pp. . Tissue factor controls the balance of angiogenic and antiangiogenic properties of tumor cells in mice. J Clin Investig. 1994;94:1320-7.

102. Tsopanoglou NE, Pipili-Synetos E, Maragoudakis ME. Thrombin promotes angiogenesis by a mechanism independent of fibrin formation. Am J Physiol. 1993;264:1302-7.

103. Dvorak HF, Senger RD, Dvorak AM, Harvey VS, McDonagh J. Regulation of extravascular coagulation by microvascular permeability. Sciencea. 1985;227:1059-61.

104. Ware LB, Kaner RJ, Crystal RG, et al. VEGF levels in the alveolar compartment do not distinguish between ARDS and hydrostatic pulmonary oedema. Eur Respir J. 2005;26(1):101-5.

105. Bandarra D, Rocha S. Tale of two transcription factors: NF-KB and HIF crosstalk. OA Mol Cell Biol. 2013;1(1):6.

106. Koong AC, Chen EY, Giaccia AJ. Hypoxia causes the activation of nuclear factor $\kappa \mathrm{B}$ through the phosphorylation of $\mathrm{I} \kappa \mathrm{B} \alpha$ on tyrosine residues. Cancer Res. 1994;54:1425-30.

107. Chen FE, Huang DB, Chen YQ, Ghosh G. Crystal structure of p50/p65 heterodimer of transcription factor NF- $\mathrm{KB}$ bound to DNA. Nature. 1998;391:410-3.

108. Carmeliet P, Dor Y, Herbert JM, et al. Role of HIF-1 alpha or in hypoxia-mediated apoptosis, cell proliferation and tumour angiogenesis. Nature. 1998;394:485-90.

109. Moritz W, Meier F, Stroka DM, et al. Apoptosis in hypoxic human pancreatic islets correlates with HIF-1alpha expression. FASEB J. 2002;16:745-7.

110. Sowter HM, Ratcliffe PJ, Watson P, et al. HIF-1-dependent regulation of hypoxic induction of the cell death factors BNIP3 and NIX in human tumors. Cancer Res. 2001;61:6669-73.

111. Greijer AE, van der Wall E. The role of hypoxia inducible factor 1 (HIF-1) in hypoxia induced apoptosis. J Clin Pathol. 2004;57(10):1009-14.

112. Krock BL, Skuli N, Simon MC. Hypoxia-induced angiogenesis: good and evil. Genes Cancer. 2011;2(12):1117-33.

Publisher's Note Springer Nature remains neutral with regard to jurisdictional claims in published maps and institutional affiliations. 